\title{
Fontes de Financiamento do Sistema ÚNICo de SAÚde
}

João Batista Lazzari ${ }^{(\star \star)}$

\section{RESUMO}

O presente estudo aborda os preceitos constitucionais do financiamento do Sistema Único de Saúde, a Emenda Constitucional n. 29/2000 e sua regulamentação, as receitas destinadas ao orçamento da Saúde e o gerenciamento desses recursos pelo Fundo Nacional de Saúde. Concluise, que o modelo de financiamento do Sistema Único de Saúde foi substancialmente aperfeiçoado com o advento da Emenda Constitucional n. 29/ 2000, com a ressalva, contudo, de que esse aperfeiçoamento ainda não significa necessariamente uma resposta satisfatória à crescente demanda por ações e serviços no campo da saúde pública.

\section{Palavras-chave}

Financiamento da Saúde, Sistema Único de Saúde, Fundo Nacional da Saúde.

\section{ABSTRACT}

This study examines the constitutional rules regarding the Unified Health System funding, the Constitutional Amendment 19/2000 and its regulation, the amount of resources designed for health and its management by

${ }^{*}$ ) Texto elaborado a partir da monografia de conclusão do Curso de Especialização em Direito Sanitário pela Universidade de Brasília - UnB, cuja integra foi publicada pela Editora LTr, em junho de 2003.

$\left(^{* \star}\right)$ Juiz Federal - TRF da 4⿳亠丷a Região, Especialista em Direito Sanitário pela Universidade de Brasília - UnB, Mestre em Ciência Jurídica pela Univali/SC, Professor da Escola da Magistratura Federal do Estado de Santa Catarina. 
the National Health Fund. It is concluded that the financing model of Unified Health System has substantially been improved from the Constitutional Amendment 29/2000, remarking, however, that does not still mean a satisfactory answer to the increasing demand for action and services in the field of public health.

\section{Key-words}

Financing of the Health, Unified Health System, Deep National of the Health.

\section{OS PRECEITOS CONSTITUCIONAIS DO FINANCIAMENTO DO SISTEMA ÚNICO DE SAÚDE}

Para a implantação do Sistema Único de Saúde (SUS) a maior dificuldade sempre foi a de um financiamento definido e suficiente para os investimentos na rede de serviços, à cobertura assistencial ambulatorial e hospitalar e às demais ações de saúde.

A Constituição Federal de 1988 preocupou-se com a necessidade de criar fontes de financiamento capazes de garantir o atendimento das ações e serviços de saúde e impôs essa responsabilidade às três esferas de governo, devendo, cada qual, assegurar o aporte regular de recursos.

Para a definição de fontes, formas e critérios de financiamento da seguridade social, e nesta compreendida a saúde, o legislador deu atenção especial ao princípio da diversidade da base de financiamento, previsto no art. 194, parágrafo único, VI, da Constituição. No entanto, o texto original da Carta Magna de 1988 não assegurou um percentual mínimo de aplicação obrigatória para o setor.

Essa omissão provocou grave crise de financiamento para a implantação do SUS, a qual foi reconhecida pela XI Conferência Nacional de Saúde, realizada em dezembro de 2000 . Ficou consignado no relatório final dessa Conferência que:

A contradição entre o modelo econômico brasileiro e a proposta de construção do SUS refletiu-se, nesses dez anos, na dificuldade de obter formas estáveis e montantes suficientes para o financiamento do sistema público de saúde, em constante atrito com a expansão de um sistema privado dirigido pela lógica excludente de mercado, coerente com o modelo de desenvolvimento hegemônico no Brasil. ${ }^{(1)}$

(1) TOJAL, Sebastião Botto de Barros [et al.]; ARANHA, Marcio lorio; e TOJAL, Sebastião Botto de Barros(org.). Manual Conceitual do Curso de Especialização em Direito Sanitário para Membros do Ministério Público e da Magistratura Federal. p. 594. 
Para Gilson Carvalho "A luta para se conseguir mais recursos para a área de saúde só terá chance de ser vitoriosa quando fizer parte de uma luta de cidadania onde todos os brasileiros estivermos reunidos: governos, prestadores, trabalhadores de saúde e cidadãos usuários dos serviços de saúde com o duplo objetivo de conseguir mais recursos e usar melhor os existentes." E prossegue afirmando que "(...) A ação de saúde é cara e de mensuração de resultados extremamente complexa."(2)

No tocante ao financiamento do SUS, a Constituição definiu que: "O sistema único de saúde será financiado, nos termos do art. 195, com recursos do orçamento da seguridade social, da União, dos Estados, do Distrito Federal e dos Municípios, além de outras fontes" (art. 198, $\S 1^{\circ}$ ).

$\mathrm{O}$ art. 195 da Constituição estabelece ainda que o financiamento da Seguridade Social é um dever imposto a toda a sociedade, de forma direta e indireta, mediante recursos provenientes dos orçamentos da União, dos Estados, do Distrito Federal, dos Municípios e de contribuições sociais.

De acordo com o princípio da diferenciação, previsto no $\S 1^{\circ}$ do art. 195 da Constituição, "as receitas dos Estados, do Distrito Federal e dos Municípios destinadas à seguridade social constarão dos respectivos orçamentos, não integrando o orçamento da União".

Em respeito aos princípios da autonomia e da integração, contidos no $\S 2^{\circ}$ do art. 195 da Constituição, "a proposta de orçamento da seguridade social será elaborada de forma integrada pelos órgãos responsáveis pela saúde, previdência social e assistência social, tendo em vista as metas e prioridades estabelecidas na lei de diretrizes orçamentárias, assegurada a cada área a gestão de seus recursos."

O tratamento constitucional dos preceitos do financiamento do SUS foi fundamental para a solidez do sistema. No entanto, a Constituição de 1988 não avançou a ponto de definir os critérios de aplicação de recursos para as ações e serviços de saúde. A Emenda Constitucional n. 29/2000 trouxe progresso neste sentido, cuja análise é objeto do item seguinte.

\section{A EMENDA CONSTITUCIONAL N. 29/2000}

Como já mencionado, a Constituição de 1988 - em sua redação original - estabeleceu que cada esfera de Governo deveria alocar recursos de seus orçamentos para o financiamento do Sistema Único de Saúde. Porém, não previu parâmetros precisos, ficando os entes federados livres para aplicar os recursos que entendiam adequados.

(2) CARVALHO, Gilson de Cássia Marques de. O financiamento público da saúde no bloco de constitucionalidade. http://www.ead.fiocruz.br/mp. 
A Emenda Constitucional n. 29, de 13.09.2000, procurou corrigir essa omissão do Constituinte de 1988, e procurou definir regras objetivas e percentuais mínimos da dotação orçamentária a serem destinados ao Sistema Único de Saúde.

Por meio da EC n. 29/2000 foi estabelecido que o orçamento federal para a saúde terá reajustes automáticos segundo a variação do valor nominal do PIB, vinculando recursos federais, do Distrito Federal, dos Estados e municípios para a saúde e fixando um percentual mínimo dos recursos próprios destes níveis de governo para aplicação imediata.

A Emenda Constitucional n. 29/2000, nos termos em que foi aprovada, provocou muitas críticas. Veja-se a respeito a posição do já citado Gilson Carvalho:

A PEC, da luta de sete anos, não é a EC-29 aprovada. A União fica responsável para garantir no mínimo $5 \%$ a mais do que os recursos empenhados em 1999 e, nos anos seguintes, a correção pelo valor nominal do PIB. Os Estados deverão investir, no mínimo, 12\% e Municípios, no mínimo $15 \%$ de seus orçamentos próprios. Quem não tiver atingido esses patamares mínimos, terá um prazo de tolerância para atingi-los, entre os anos de 2000 e 2004. Deverão iniciar, no mínimo, com $7 \%$ em 2000, e nos anos seguintes, cobrir a diferença. Nestas siglas e percentuais esconde-se uma postura de governo de, mais uma vez, deixar o social à deriva. (...) As autoridades econômicas, com o beneplácito de FHC, desresponsabilizaram a União e descarregaram mais ônus sobre Estados e Municípios. Diminuíram os recursos de contribuição da União para a saúde e aumentaram os percentuais de Estados e Municípios. ${ }^{(3)}$

A XI Conferência Nacional de Saúde apresentou um diagnóstico mais favorável quanto aos efeitos da referida Emenda Constitucional. Consta do Relatório Final da Conferência que:

E, neste ano 2000, a conquista da aprovação da Emenda Constitucional 29/2000, ainda que não represente a forma ideal desejada pelo setor, cria horizontes mais favoráveis quanto aos montantes destinados à saúde e coloca desafios para o controle social quanto ao melhor e mais adequado destino dos recursos acrescidos. As principais restrições à EC 29/00 estão associadas ao fato de não vir acompanhada de uma regulamentação imediata que garanta um significativo aumento dos recursos na área da saúde, principalmente pelas indefinições sobre o que será admitido como gastos em ações e serviços de saúde. ${ }^{(4)}$

(3) CARVALHO, Gilson de Cássia Marques de. O financiamento público federal do sistema único de saúde. Disponivel em http://www.ead.fiocruz.br/mp.

(4) TOJAL, Sebastião Botto de Barros Tojal. Op. cit., p. 594. 
Embora a EC n. 29/2000 não tenha sido aprovada na forma como pretendida pelos especialistas da área, ela significou um grande avanço na alocação de recursos orçamentários a serem destinados às ações e serviços de saúde. De acordo com Ana Maria Malik, "[u]ma estimativa do Ministério da Saúde aponta a possibilidade de crescimento de mais de $40 \%$ dos recursos dos três níveis de governo, entre 1998 e 2004, destinados a Ações e Serviços de Saúde. Desse total, os governos estaduais deverão ampliar seus gastos em mais de $60 \%$, seguidos pelos municípios com $28 \%$ em relação aos valores de 1998 (Brasil, 2001 e 2001c)."(5)

\section{A REGULAMENTAÇÃO DA EMENDA CONSTITUCIONAL N. 20/98}

Para a regulamentação da EC n. 20/98 ficou estabelecido pelo art. 198, $\S 3^{\circ}$, da Constituição a necessidade de lei complementar que estabeleça, entre outras matérias: os percentuais de participação dos entes federados a partir de 2005; os critérios de rateio dos recursos da União vinculados à saúde destinados aos Estados, ao Distrito Federal e aos municípios, e dos Estados destinados a seus respectivos municípios, objetivando a progressiva redução das disparidades regionais; as normas de fiscalização, avaliação e controle das despesas com saúde nas esferas federal, estadual e municipal e as normas de cálculo do montante a ser aplicado pela União.

A Lei Complementar em referência ainda não foi aprovada pelo Congresso Nacional, e poderá demorar em face da complexidade da matéria e dos conflitos de interesses, pois envolvem destinação de recursos públicos de grande monta.

Todavia, o Conselho Nacional de Saúde entendeu serem auto-aplicáveis os dispositivos da EC n. 29/2000. Com esse entendimento e, diante da necessidade de esclarecimento conceitual e operacional do texto constitucional, de modo a lhe garantir eficácia e viabilizar sua perfeita aplicação pelos agentes públicos até a aprovação da Lei Complementar a que se refere $\circ \S 3^{\circ}$ do art. 198 da Constituição, aprovou, com essa finalidade, a Resolução n. 316, de 04 de abril de 2002.

Enquanto não aprovada a norma legal reclamada, a partir do exercício financeiro de 2005, continuarão a ser aplicados à União, aos Estados, ao Distrito Federal e aos municípios os critérios transitórios definidos pela EC n. 29/2000, consoante previsão expressa contida no art. 77 , § $4^{\circ}$ do ADCT.

A apuração dos valores mínimos a serem aplicados em ações e serviços públicos de saúde, de que tratam o art. 198, $\S 20$ da Constituição Federal e o art. 77 do ADCT, dar-se-á a partir das seguintes bases de cálculo(6):

(5) Idem, ibidem, p. 521.

(6) As bases de cálculo citadas encontram-se referidas na Resolução n. 316, de 04 de abril de 2002, do Conselho Nacional de Saúde. 


\section{União}

No ano 2000, o montante empenhado em ações e serviços públicos de saúde no exercício financeiro de 1999, acrescido de, no mínimo, cinco por cento.

De 2001 a 2004, o valor apurado no ano anterior, corrigido pela variação nominal do Produto Interno Bruto - PIB.

A expressão "o valor apurado no ano anterior", prevista no art. 77, II, $b$, do ADCT, é o montante efetivamente empenhado pela União em ações e serviços públicos de saúde no ano imediatamente anterior, desde que garantido o mínimo assegurado pela Emenda Constitucional para o ano anterior.

\section{Estados e Distrito Federal}

Doze por cento do produto da arrecadação dos impostos a que se refere $o$ art. 155 e dos recursos de que tratam os arts. 157 e 159, inciso I, alínea $a$, e inciso II, da Constituição Federal, deduzidas as parcelas que forem transferidas aos respectivos municípios.

$\mathrm{Na}$ apuração da base de cálculo dos Estados deve ser observada a seguinte fórmula:

- Total das receitas de impostos de natureza estadual: ICMS, IPVA, ITCMD

(+) Receitas de transferências da União: Quota-Parte do FPE, CotaParte do IPI - Exportação, Transferências da Lei Complementar n. 87/ 96 (Lei Kandir)

\section{(+) Imposto de Renda Retido na Fonte - IRRF}

(+) Outras receitas correntes: Receita da Dívida Ativa Tributária de Impostos, Multas, Juros de Mora e Correção Monetária

(-) Transferências financeiras constitucionais e legais a municípios: ICMS (25\%), IPVA (50\%), IPI - Exportação (25\%)

(=) Base de Cálculo Estadual

\section{Municípios e Distrito Federal}

Quinze por cento do produto da arrecadação dos impostos a que se refere o art. 156 e dos recursos de que tratam os arts. 158 e 159, inciso I, alínea $b$ e $\S 3^{\circ}$, da Constituição Federal. 
No caso dos municípios deve se proceder da seguinte forma:

- Total das receitas de impostos municipais: ISS, IPTU, ITBI

(+) Receitas de transferências da União: Quota-Parte do FPM, QuotaParte do ITR, Quota-Parte da Lei Complementar n. 87/96 (Lei Kandir)

\section{(+) Imposto de Renda Retido na Fonte - IRRF}

(+) Receitas de transferências do Estado: Quota-Parte do ICMS, Quota-Parte do IPVA, Quota-Parte do IPI - Exportação

(+) Outras Receitas Correntes: Receita da Dívida Ativa Tributária de Impostos, Multas, Juros de Mora e Correção Monetária

\section{(=) Base de Cálculo Municipal}

Para os Estados e os municípios, até o exercício financeiro de 2004, foi observada a regra de evolução progressiva de aplicação dos percentuais mínimos de vinculação, prevista no art. 77 do ADCT. Os entes federados cujo percentual aplicado em 2000 tiver sido não superior a sete por cento deveriam aumentá-lo de modo a atingir o mínimo previsto para os anos subseqüentes, conforme o quadro que segue:

\begin{tabular}{|c|c|c|}
\hline \multicolumn{3}{|c|}{ Percentuais Mínimos de Vinculação } \\
\hline Ano & Estado & Municipios \\
\hline 2000 & $7 \%$ & $7 \%$ \\
\hline 2001 & $8 \%$ & $8,6 \%$ \\
\hline 2002 & $9 \%$ & $10,2 \%$ \\
\hline 2003 & $10 \%$ & $11,8 \%$ \\
\hline 2004 & $12 \%$ & $15 \%$ \\
\hline
\end{tabular}

A apuração da base de cálculo do Distrito Federal é definida pelo somatório do percentual de vinculação correspondente aos Estados aplicado sobre a base estadual com o percentual de vinculação correspondente aos municípios aplicado sobre a base municipal, seguindo a regra de progressão prevista no art. 77 da ADCT.

Os entes federados que em 2000 já aplicavam percentuais superiores a sete por cento não poderiam reduzi-lo, retornando aos sete por cento. A diferença entre o efetivamente aplicado e o percentual final estipulado no texto constitucional deveria ser abatida na razão mínima de um quinto ao ano, até 2003, sendo que em 2004 deva ser, no mínimo, o previsto no art. 77 do ADCT.

Do exposto, concluiu-se que a Emenda Constitucional n. 29/2000, ao definir nova sistemática de cálculo para apuração dos recursos mínimos a serem aplicados em saúde pelos entes federados, proporcionou significa- 
tivo aumento das dotações orçamentárias para o financiamento do Sistema Único de Saúde.

Há muito que ser feito, no entanto, para o incremento necessário na dotação orçamentária da saúde no Brasil, principalmente em nivel federal. Considerando-se que nos últimos anos a arrecadação de tributos pela União tem apresentado crescimento expressivo, a adoção da proporcionalidade de distribuição de receitas proporcionaria um aumento substancial dos valores vertidos para o SUS.

\section{OUTRAS RECEITAS DO SISTEMA ÚNICO DE SAÚDE}

Constituem-se, também, fontes de recursos do Sistema Único de Saúde as receitas previstas no art. 32 da Lei n. 8.080/90 (Lei Orgânica da Saúde) que são provenientes de:

a) serviços que possam ser prestados sem prejuízo da assistência à saúde;

b) ajuda, contribuições, doações e donativos;

c) alienações patrimoniais e rendimentos de capital;

d) taxas, multas, emolumentos e preços públicos arrecadados no âmbito do Sistema Único de Saúde (SUS); e

e) rendas eventuais, inclusive comerciais e industriais.

A LOS prevê, também, que as ações de saneamento básico executadas supletivamente pelo SUS serão financiadas com recursos do Sistema Financeiro de Habitação (art. $32, \S 3^{\circ}$ ). Por sua vez, as atividades de pesquisa e desenvolvimento científico e tecnológico em saúde serão co-financiadas pelo SUS, pelas universidades e pelo orçamento fiscal $^{(7)}$, além de recursos de instituições de fomento e financiamento ou de origem externa e receita própria das instituições executoras (art. $32, \S 5^{\circ}$ ).

Outra fonte de recursos de significativa importância para o SUS é o repasse de $50 \%$ (cinqüenta por cento) do Seguro Obrigatório de Veículos Automotores Terrestres (DPVAT), previsto na Lei n. 6.194/74. O DPVAT é pago no momento da quitação do Imposto de Propriedade de Veículos Automotores (IPVA), o qual, por ser um imposto estadual, obedece a prazos de pagamento definidos pelos Estados, cujo calendário pode ser alterado anualmente.

(7) Orçamento Fiscal: Está contido na lei orçamentária anual e se refere aos Poderes da União, seus fundos, órgãos e entidades da administração direta e indireta, inclusive fundações instituídas e mantidas pelo poder público. 
Como se pode verificar das diversificadas fontes de receitas, o legislador, ao instituir contribuições exigidas dos mais variados segmentos da sociedade, atentou para a observância do princípio da diversidade da base de financiamento do Sistema Único de Saúde. Isso não que dizer, todavia, que os recursos arrecadados sejam suficientes para a crescente demanda por ações e serviços no campo da saúde pública. Por isso, a pertinência de constantes estudos e pesquisas nesta área no sentido de aprimorar o sistema e adequálo às legitimas exigências dos milhões de brasileiros que dele dependem.

\section{O FUNDO NACIONAL DE SAÚDE}

O Fundo Nacional de Saúde (FNS) funciona como agente financeiro do SUS, sendo os seus recursos destinados a prover as despesas correntes e de capital do Ministério da Saúde, seus órgãos e entidades da administração indireta, as transferências para a cobertura de ações e serviços de saúde, a serem executados pelos municípios, Estados e Distrito Federal, e outras autorizadas pela Lei Orçamentária Federal, em consonância com o Plano Qüinqüenal do Ministério da Saúde (art. $2^{\circ}$ da Lei n. 8.142/90).

Os recursos que integram o FNS possuem origens diversas, que podem ser relacionadas da seguinte forma:

- consignações do Orçamento da Seguridade Social destinadas, conforme o disposto no art. 34 da Lei n. 8.080/90, para as despesas e transferências estabelecidas no art. $2^{\circ}$ da Lei n. 8.142/93;

- consignações do Orçamento Fiscal da União;

- decorrentes de créditos adicionais;

- decorrentes de doações de organismos internacionais vinculadas à Organização das Nações Unidas e de entidades de cooperação técnica e de financiamentos e empréstimos;

- resultados de aplicações financeiras na forma da legislação vigente;

- outras fontes, de acordo com o art. 32 da Lei n. 8.080/90;

- da contribuição provisória sobre movimentação ou transmissão de valores e de créditos de natureza financeira (CPMF);

- $50 \%$ do valor bruto do Seguro Obrigatório de Veículos Automotores Terrestres (DPVAT)

Das contribuições elencadas, a CPMF tem participação expressiva no custeio das ações e serviços de saúde, em face do volume arrecadado e da destinação prevista pela Emenda Constitucional n. 37/2002 (dos 0,38\%, $0,20 \%$ destinam-se ao Fundo Nacional de Saúde) $)^{(8)}$. Embora seja fonte subsidiária, ela foi responsável pela regularização dos fluxos de recursos destinados à saúde pública nos últimos anos. Assim, a manutenção dessa contribuição, embora o tema seja objeto de renhido debate no plano políti- 
co, é opção que não se deveria abandonar sem um exame mais detido das conseqüências da sua supressão.

O FNS vem sendo paulatinamente organizado em conformidade com as diretrizes e os objetivos do Sistema Único de Saúde, servindo de importante paradigma para a organização nos Estados e municípios dos respectivos fundos de saúde.

Cabe destacar, finalmente, que todos os esforços na arrecadação dos recursos destinados às ações e serviços de saúde cairão por terra se não forem eles geridos sob impermeável manto ético e total transparência.

\section{CONCLUSÃO}

O modelo de financiamento do Sistema Único de Saúde foi substancialmente aperfeiçoado com o advento da Emenda Constitucional n. 29/ 2000 , com a ressalva, contudo, de que esse aperfeiçoamento ainda não significa necessariamente uma resposta satisfatória à crescente demanda por ações e serviços no campo da saúde pública.

\section{REFERÊNCIAS BIBLIOGRÁFICAS}

BRASIL. Constituição da República Federativa do Brasil de 05 de outubro de 1988. Disponivel em http://www.senado.gov.br/legislação. Acesso em 14.05.2004.

. Lei n. 8080 de 19 de setembro de 1990. Dispõe sobre as condições para a promoção, proteção e recuperação da saúde, a organização e o funcionamento dos serviços correspondentes e dá outras providências. Disponivel em http://www.senado.gov.br/legislação. Acesso em 14.05.2004.

. Conselho Nacional de Saúde. Resolução n. 316, de 04 de abril de 2002. Disponível em http://www.ead.fiocruz.br/mp. Acesso em 14.05.2004.

CARVALHO, Gilson de Cássia Marques de. O financiamento público da saúde no bloco de constitucionalidade. http://www.ead.fiocruz.br/mp.

. O financiamento público federal do sistema único de saúde. www.ead.fiocruz.br/mp.

LAZZARI, João Batista. As Fontes de Financiamento do Sistema Único de Saúde. São Paulo: LTr, 2003.

TOJAL, Sebastião Botto de Barros Tojal [et al.]; ARANHA, Marcio lorio; e TOJAL, Sebastião Botto de Barros (org.). Manual Conceitual do Curso de Especialização em Direito Sanitário para Membros do Ministério Público e da Magistratura Federal. Brasília: UnB, 2002.

(8) A Emenda Constitucional n. 42/2003 prorrogou a cobrança da CPMF até 31.12.2007. 